Rabaska

Revue d'ethnologie de l'Amérique française

\title{
Musées et expositions
}

\section{Jocelyne Milot}

Numéro 1, 2003

URI : https://id.erudit.org/iderudit/201633ar

DOI : https://doi.org/10.7202/201633ar

Aller au sommaire du numéro

Éditeur(s)

Société québécoise d'ethnologie

ISSN

1703-7433 (imprimé)

1916-7350 (numérique)

Découvrir la revue

Citer ce document

Milot, J. (2003). Musées et expositions. Rabaska, (1), 211-216.

https://doi.org/10.7202/201633ar

Ce document est protégé par la loi sur le droit d'auteur. L'utilisation des services d'Érudit (y compris la reproduction) est assujettie à sa politique d'utilisation que vous pouvez consulter en ligne.

https://apropos.erudit.org/fr/usagers/politique-dutilisation/
Cet article est diffusé et préservé par Érudit.

Érudit est un consortium interuniversitaire sans but lucratif composé de l'Université de Montréal, l'Université Laval et l'Université du Québec à Montréal. Il a pour mission la promotion et la valorisation de la recherche. https://www.erudit.org/fr/ 


\section{Musées et expositions}

JoCelyne MiLot

Musée du Royal 22 ${ }^{\mathrm{c}}$ Régiment, Québec

Cette rubrique présentera, année après année, la fiche descriptive des musées d'ethnologie de l'Amérique française avec les expositions récemment tenues. Elle prendra peu à peu de l'importance.

Musée de la civilisation

85, rue Dalhousie

Québec (Québec) G1K 7A6
Téléphone : (418) 643-2158

Télécopieur : (418) 646-9705

Courriel : mcqweb@mcq.org Toile : www.mcq.org

Musée fondé en 1988.

Type : histoire et société ; musée thématique d'envergure internationale.

Mission : musée d'État responsable de l'animation et de la gestion de cinq sites, dont le Musée de l'Amérique française (ses origines remontent à 1806) et Place Royale.

Collection : 217855 artefacts : arts décoratifs, beaux-arts, histoire humaine, sciences naturelles, documents d'archives.

Services à la clientèle: expositions, conférences, concerts, recherche, programmes éducatifs, animation, publications, restauration.

\section{Musée de la civilisation}

Expositions permanentes : Mémoires et Nous, les Premières Nations.

Expositions temporaires: La Langue pendue (atelier) ( $1^{\text {er }}$ mai 2002 au 30 septembre 2003). Découverte du patrimoine vivant qu'est la langue à travers des jeux d'animation, des devinettes, des jeux de définitions. Parole de peau (27 novembre 2002 au 2 septembre 2003). La peau comme témoin de notre vie sociale et privée. Des collections nord-américaines et européennes nous permettent de découvrir la peau comme signifiant. Cowboy dans l'âme (10 avril 2002 au 15 mars 2003). Plus qu'une exposition sur les cowboys, il s'agit de l'étude d'un mythe, celui de l'espace et du désir de liberté. Tout au long d'un parcours historique et ethnologique, on découvre le phénomène country ou western, une manière d'être et de vivre ancrée dans l'âme 
américaine. Nombreux symboles présents dans l'exposition à travers des sonorités, des objets, des films, des vedettes (chanteurs, danseurs, acteurs) et le monde du rodéo.

\section{Musée de l'Amérique française}

Expositions permanentes : Amérique française et Histoire des collections du Séminaire de Québec.

Musée québécois de culture populaire Téléphone : (819) 372-0406 200 , rue Laviolette Télécopieur : (819) 372-9907 Trois-Rivières (Québec) G9A 5L2 Courriel : info@culturepop.qc.ca et info@enprison.com

Type : musée thématique, histoire et culture.

Mission : musée voué à la connaissance de la société québécoise et à sa culture. Le musée a ouvert ses portes le 20 juin 2003. La première thématique exploitée porte sur l'alimentation ( $Q u e ́ b e c$ all dressed). On y met aussi en vedette des œuvres majeures de l'art populaire québécois ancien et actuel (Double vie; Faire de l'air). Une quatrième exposition porte sur la région mauricienne (Vivre ici) ; une cinquième (L'Ogre de la forêt à Gaultier) est destinée aux enfants ; une dernière (La Réserve ouverte Robert-Lionel Séguin) montre au public les 70000 objets de la collection.

Activité : En prison. Depuis août 2002, on propose une visite expérience dans l'ancienne prison de Trois-Rivières rattachée au Musée. Celle-ci plonge le visiteur dans la vie carcérale des années 1960 et 1970. Les guides, euxmêmes des ex-détenus, répondent aux questions des visiteurs et leur transmettent des témoignages de première main.

Musée canadien des civilisations

100 , rue Laurier

Gatineau (Québec) J8X 4H2
Téléphone : (819) 776-7000

Télécopieur : (819) 776-8300

Toile : www.civilisations.ca

Musée fondé en 1986. L'histoire du MCC remonte à la création de la Commission géologique du Canada en 1842.

Type : histoire de l'humanité et histoire canadienne.

Mission : promouvoir chez tous les Canadiens un sens de leur identité et de leur histoire communes et favoriser le dialogue interculturel au pays. 
Collection : 5000000 d'artefacts : archéologie (préhistoire canadienne), ethnologie (cultures amérindienne, inuit et métis), culture traditionnelle (traditions populaires et multiculturalisme), histoire ( patrimoine de la vie quotidienne au Canada).

Services à la clientèle : recherches, programmes éducatifs, publications et produits dérivés.

Expositions : Résonance - Patrimoine musical de la francophonie (10 mai 2001 au 23 mars 2003). Événement culturel qui vise à faire découvrir des instruments de musique provenant des pays membres de la Francophonie, de même que les liens qui existent entre le sport et les pratiques musicales. Présentation de plus de 140 instruments issus de 4 continents. Facile, économique et sans risque - L'achat par catalogue au Canada (14 juin 2002 au 13 octobre 2003). Une exposition qui examine le rôle joué par l'achat par catalogue dans la plupart des foyers canadiens. C'est un regard posé sur la société de la fin du $\mathrm{XIX}^{e}$ siècle qui était à l'aube de l'ère de la consommation de masse. Sous le signe de la croix (jusqu'au 18 mars 2001). L'expression créative du christianisme au Canada.

\section{Musée McCord}

690 ouest, rue Sherbrooke

Montréal (Québec) H3A 1E9
Téléphone : (514) 398-7100

Télécopieur : (514) 398-5045

Toile :www.musee-mccord.qc.ca

Musée fondé en 1921.

Type : histoire et culture matérielle.

Mission : faire connaître l'histoire sociale et la culture matérielle de Montréal, du Québec et du Canada. Période couverte : XVIII' siècle à aujourd'hui.

Collection : 963900 objets : ethnologie, archéologie, costumes, textiles, archives photographiques, dont le fonds Notman, peintures, dessins, estampes, arts décoratifs.

Services à la clientèle : visites guidées, visites scolaires, activités culturelles, publications et accès à la base de données sur la toile comptant 24000 références.

Exposition : LUI - La mode au masculin (17 mai 2002 au 5 janvier 2003). Vanité ? Nécessité ? Qu'est-ce qui motive les hommes dans le choix de leurs vêtements ? Les hommes, contrairement à la croyance populaire, s'intéressent à la mode et cette exposition pose un regard sur 300 ans de traditions vestimentaires masculines. 
Musée d'histoire du Lac-Saint-Jean

54, avenue Saint-Joseph

Alma (Québec) G8B 5W1
Téléphone : (418) 668-2606

Télécopieur : (418) 668-5851

Courriel : shlsj@shlsj.org

Musée fondé en 1986. Fermé en 2003 en raison du déménagement.

Type : histoire régionale.

Mission : faire connaître l'impact de la période industrielle sur la société régionale et mettre en valeur une collection acquise en 1975. Période couverte : 1850 à 1970 .

Collection : 2000 objets : arts décoratifs, histoire humaine, archives.

Services à la clientèle : archives régionales, animations pédagogiques, ateliers, expositions, publications et produits dérivés.

Exposition permanente: Passage. Retrace les grands mouvements de l'occupation humaine sur le territoire jeannois, de la préhistoire à la modernité. Exposition temporaire : Une vie comme un cirque (octobre 2002). Portrait d'Adrien Tremblay, amuseur public originaire du Saguenay-Lac-Saint-Jean. Sous le nom d'Adriano, il fonde une troupe d'amuseurs publics qui sillonnera le Québec entre 1930 et 1940.

Musée régional de Vaudreuil-Soulanges Téléphone : (450) 455-2092 431, avenue Saint-Charles

Toile : www.mrvs.qc.ca

Vaudreuil-Dorion (Québec) J7V 2N3

Musée fondé au début des années 1950.

Type : histoire régionale.

Mission : préserver et mettre en valeur les éléments liés à l'évolution de l'art de vivre dans Vaudreuil-Soulanges. Accent mis sur le régime seigneurial ainsi que sur le travail et l'héritage des fabricants d'appelants québécois. Période couverte : début de la colonisation à aujourd'hui.

Collection : 6000 objets : objets de la vie quotidienne, instruments traditionnels, outils et œuvres d'art.

Services à la clientèle : expositions, ateliers d'animation, concerts.

Expositions : À chacun son métier (jusqu'au 26 février 2001). Exposition évoquant une trentaine de métiers traditionnels au moyen d'outils et d'objets de production artisanale provenant de la collection du musée. Jour après jour (jusqu'au 24 juin 2002). La période 1860 à 1940 évoquée à partir d'objets reliés aux tâches domestiques. Edmond-J. Massicotte, artiste-dessinateur (jusqu'au 23 décembre 2002) et Albert Demers, sculpteur-animalier. De l'hippomobile à l'automobile (jusqu'au 21 septembre 2003). 


\section{Musée du Bas-Saint-Laurent}

330 , rue Saint-Pierre

Rivière-du-Loup (Québec) G5R 3V3
Téléphone : (418) 862-7547

Télécopieur : (418) 862-3019

Musée fondé en 1975.

Type : art contemporain et ethnologie.

Mission : éducation des clientèles et intervention auprès de la population de la région dans le domaine de l'art contemporain québécois et de l'ethnologie. Collection : 150000 artefacts : beaux-arts, histoire humaine, ethnologie, archéologie, négatifs anciens et photographies.

Services à la clientèle : recherches, programmes éducatifs, visites guidées, publications, produits dérivés.

Expositions : Chassé-croisé. Art populaire et art indiscipliné (26 janvier au 13 avril 2003). Présentation comparée d'œuvres de huit artistes populaires traditionnels (Arthur Bouchard, Edmond Châtigny, Yvon Côté, Léo Fournier, Oscar Héon, Honoré Hunt, Félicien Lévesque, Arthur Villeneuve) avec celles de six artistes dits indisciplinés (Bill Anhang, Dominique Engel, Richard Greaves, Victor Henry, Charles Lacombe, Palmerino Sorgente). J. -Adélard Boucher, objectif-horizons (5 mai 2002 au 30 avril 2003). Présentation de photographies anciennes qui posent un regard sur l'évolution familiale et la vie maritime de la région.

\section{Musée de Charlevoix}

10, Chemin du Havre
Téléphone : (418) 665-4411

Télécopieur : (418) 665-4560

La Malbaie (Québec) G5A 2Y8 Courriel : museedecharlevoix@bellnet.ca

\section{Musée fondé en 1977.}

Type : musée régional spécialisé.

Mission : diffuser l'art populaire d'ici et d'ailleurs en plus de conserver, diffuser et mettre en valeur le patrimoine ethnologique, artistique et historique de la région.

Collection : 6000 artefacts : arts décoratifs, beaux-arts, histoire humaine et sciences naturelles, art populaire de la région, archives.

Services à la clientèle : recherche, programmes éducatifs, publications, produits exclusifs des artisans de la Corporation des métiers d'art en Charlevoix. Exposition : Sculpteurs populaires du Québec (1 ${ }^{\text {er }}$ juin 2002 au 30 septembre 2003).

Mise en valeur de l'importante collection d'art populaire donnée au Musée par Serge Brouillard et Carole Noël. 137 sculptures populaires provenant de toutes les régions du Québec. 


\section{Musée des religions}

900, boulevard Louis-Fréchette

Nicolet (Québec) J3T 1V5 Courriel : musee@museedesreligions.qc.ca
Téléphone : (819) 293-6148

Télécopieur : (819) 293-4161

Musée fondé en 1982 et ouvert au public depuis 1986.

Type : histoire, ethnographie et art religieux.

Mission : mettre en évidence le caractère communautaire et populaire de l'expérience religieuse par la mise en valeur d'objets témoins de la dimension spirituelle de l'être humain.

Collection : 5000 artefacts : objets ethnologiques à caractère religieux, arts décoratifs, beaux-arts, histoire humaine.

Services à la clientèle : expositions, conférences, concerts, recherches, programmes éducatifs, animation, publications .

Exposition : Culte et collection (19 décembre 2001 au 30 septembre 2003). Présentation des objets de la collection appartenant aux cinq grandes traditions religieuses du Québec.

\section{Écomusée du fier monde}

2050, rue Amherst

Montréal (Québec) H2L 3L8
Téléphone : (514) 528-8444

Télécopieur : (514) 528-8686

Courriel : ecomusee@globetrotter.net

Corporation fondée en 1981 et écomusée depuis 1996.

Type : histoire industrielle et ouvrière.

Mission : mettre en valeur trois éléments qui sont l'industrie, le travail et la culture ; développer le segment de l'histoire industrielle et ouvrière de Montréal et, plus particulièrement, du quartier Centre-Sud ; faire de l'histoire et du patrimoine un moyen d'éducation populaire et un levier du développement local.

Collection : 600 artefacts : objets de cérémonie, de technologie, de sport, photographies et documents.

Services à la clientèle : programmes éducatifs, visites guidées, circuits patrimoniaux, publications.

Exposition: Une pinte d'histoire. Le lait à Montréal (16 octobre 2002 au 8 septembre 2003). Présentation des multiples facettes de l'histoire du lait, de la transformation à la consommation. 